\title{
Notas sobre a dissimulação honesta
}

Notes on truthful dissimulation

MÍSSIO, Edmir. A civilidade e as artes de fingir: a partir do conceito de dissimulação honesta de Torquato Accetto. São Paulo: EDUSP, 2012, 245 p.

\section{Cleber Vinicius do Amaral Felipe}

clebervafe@gmail.com

Doutorando

Universidade Estadual de Campinas

Rua Cora Coralina, s/n - Barão Geraldo

13083-896 - Campinas - SP

Brasil

Palavras-chave

Ética; Retórica; História dos conceitos.

Keywords

Ethics; Rhetoric; History of concepts. 
Aos olhos do leitor que se ocupa desta resenha, o termo "dissimulação honesta" pode denotar uma contradição. Esta contradição se torna verossímil a partir do século XIX, momento no qual a honestidade veicula-se aos assuntos pessoais descompromissados com a aparência pública, por exemplo. O ajuste prudente às circunstâncias, entendido como ato decoroso que concede licença para o uso de máscaras em uma sociedade de corte, passa a ser visto como "mentira e artifício em face da verdade profunda, interna, subjetiva que dotou de complexidade psicológica a noção de sujeito nos séculos XIX e XX" (PÉCORA 2001 , p. XIX). No século da ilustração, com Kant, a "mentira útil" perde sua legitimidade, de forma que a verdade "constitui-se imperativo categórico estruturante de toda a relação com o outro, uma das condições formais do direito e da vida em sociedade, da civilidade moderna" (SEIXAS 2005, p. 417). São vários, portanto, os desafios de um pesquisador que, em pleno século XXI, busca analisar as ruínas de um conceito há muito perdido e/ou desacreditado.

No livro A civilidade e as artes de fingir: a partir do conceito de dissimulação honesta "de" Torquato Accetto, publicado pela EDUSP no ano de 2012, Edmir Míssio estuda o conceito de dissimulação honesta a partir, sobretudo, do tratado moral Della dissimulazione onesta (1641), de Torquato Accetto. Como é o final do trabalho que efetivamente determina o seu começo, Míssio admite, nas conclusões, que seu estudo "emulou o seu objeto por meio de jogos de palavras e especialmente pelo recurso a copiosa citação" (MÍSSIO 2012, p. 175). No entanto, o leitor do tratado accettiano e do livro que esta resenha toma por objeto 242 não encontra material indigesto, mas estudo agudo orientado por um mesmo conceito, que o título de Accetto e o subtítulo de Míssio nomeiam: dissimulação honesta. Assim, A civilidade e as artes de fingir não é um estudo propriamente sobre Accetto, mas sobre a matéria prima de seu tratado: matéria esta que ecoa nos escritos de outros autores e que, também, é eco de concepções e conceitos antigos que, reciclados, Ihe deram nome e fundamento.

Edmir Míssio não descarta o costume do gênero e leva em consideração os argumentos e articulações da arte accettiana. O primeiro capítulo lida com o ethos do secretário, ofício do tratadista estudado, e com a técnica da escrita de cartas, que o secretário deveria dominar. O autor estuda uma produção letrada que Accetto muito provavelmente conhecia. No capítulo dois, encontramos reflexões sobre o gênero epidítico (ou demonstrativo) e sobre o gênero do tratado, o que requer do autor conhecimento de diversas referências antigas e de figuras e procedimentos de elocução, como o uso de exemplos, analogias, metáforas, ironias, citações, sentenças. Míssio mostra que, reciclando a tópica da brevitas, Accetto recorre a uma escrita "baseada em um composto de clareza e obscuridade análogo ao conceito formulado e à ação elogiada e preconizada" (MÍSSIO 2012, p. 60). Em outras palavras, Torquato Accetto não apenas escreve sobre a dissimulação honesta, mas dissimula honestamente ao longo de seu tratado para mostrar, na prática, os elementos que prescreve.

No terceiro capítulo, Míssio retoma o conceito aristotélico de prudência (phrônesis) e as categorias ciceronianas dissimulatio e honestas, com o intuito de polir melhor o conceito "de" Torquato Accetto. Utilizo as aspas, 
aqui, para imitar o procedimento do autor, que também as utiliza no subtítulo de seu livro. Na conclusão, ele lembra que a "dissimulação honesta pode ser união de palavras em Accetto e Refuge, mas é pensamento (enquanto fingimento não danoso) contido já em Homero, Xenofonte, Platão etc., tendo obviamente perpassado incontáveis mentes" (MÍSSIO 2012, p. 174). Ainda no terceiro capítulo, deparamo-nos com um estudo dos tratados de civilidade de Baldassare Castiglione e Giovanni Della Casa, sendo que o primeiro chega a nomear um procedimento que faz largo uso da dissimulação, a saber, a sprezzatura, que "opera pela dissimulação ao esconder a arte e demonstrar facilidade no fazer e dizer" (MÍSSIO 2012, p. 103). O conceito accettiano, para Míssio, apoia-se "em bases retórico-ético-teológicas das quais não pode ser dissociado, e tem como uma de suas funções principais a manutenção da paz por meio do decoro e das boas maneiras, em meio às amabilidades e agudezas" (MÍSSIO 2012, p. 111).

No quarto capítulo, visualizamos possíveis nexos entre o conceito accettiano de dissimulação honesta e concepções partilhadas por Maquiavel, Gracián, Giovanni Botero, Pedro de Rivadeneira e Saavedro Fajardo. Tomemos, por exemplo, o caso de Maquiavel: para ele, a arte da aparência, crucial no domínio da política, associa o ethos do príncipe à persuasão dos demais integrantes do Estado: "os homens são tão ingênuos e tão submetidos às necessidades do momento que o enganador sempre encontrará quem se deixe enganar" (MAQUIAVEL 1996, p. 129-130). Ao contrário do príncipe prudente, o vulgo tende a prender sua atenção e a render elogios às aparências, ou seja, encontrase em situação de se deixar manipular pelo príncipe, pois direciona seu olhar aos artifícios, às feições do objeto de sua contemplação.

Giovanni Botero, por sua vez, atribui um papel central à Igreja Católica no que se refere à submissão do súdito ao príncipe, e legitima o uso da dissimulação, sobretudo enquanto forma de instaurar o segredo e manter a riputazione do príncipe. O jesuíta espanhol Pedro de Rivadeneira afirma que a dissimulação honesta só é legítima quando praticada por "verdadeiros cristãos", condenando enfaticamente a simulação, a hipocrisia e a mentira. Para Saavedra Fajardo, a dissimulação "de fins lícitos" é conveniente quando manuseada pelo príncipe, funcionando como um escudo contra a adulação. Baltasar Gracián, por fim, ao retratar a discrição dos homens de Corte do século XVII, adverte: "na falta de força, use a destreza. Siga qualquer um dos dois caminhos: o real, de valor, ou o atalho do artifício" (GRACIÁN 1998, p. 109). Como indica Míssio, o discreto de Gracián é "composto de gênio e engenho, sabedoria e valentia no entender, capacidades providas pela natureza e realçadas pela arte" (MÍSSIO 2012, p. 138). Em teoria, como nos indica Hansen, o discreto católico "não poderia mentir ou ser hipócrita. Na prática, contudo, as condutas adaptam-se às conveniências da ocasião, o que determina um duplo padrão de moralidade e o típico casuísmo jesuítico das interpretações" (HANSEN 1996, p. 87).

Retomando os dizeres estoicos, Accetto afirma que os homens "fazem-se semelhantes aos lobos, infiéis, pérfidos e insidiosos; outros semelhantes 
aos leões, brutais, ferozes e truculentos, e enfim, a maior parte de nós torna-se semelhante às raposas" (ACCETTO 2001, p. 41). A astúcia, representada pela raposa, geralmente retrata a fraude, mas, em alguns sentidos, remonta também à métis de Ulisses que, para Accetto, pode muito bem configurar uma ação prudente. A virtude da prudência, inclusive, é central nos escritos destes autores, pois somente o homem prudente é capaz de fazer reto uso da dissimulação.

O quinto e último capítulo realiza um breve levantamento de questões relativas à composição de Accetto, retomando pressupostos maquiavélicos e noções presentes em Sêneca para, mais adiante, tratar da tópica do "coração oculto", largamente difundida nos escritos cristãos. Ele trabalha, por exemplo, com a tópica da paciência, presente em Maquiavel e em Accetto (MÍSSIO 2012, p. 153-154), e com a possibilidade de uma simulação válida, honesta, pois movida para efetivação de um propósito reto (MÍSSIO 2012, p. 155-157). Não é de se estranhar que a dissimulação honesta esteja presente nas teorizações sobre a razão de Estado e nos tratados de civilidade, já que pode ser entendida como "medida excepcional, remédio e arte virtuosa de governo, cujo uso depende da ocasião" (MÍSSIO 2012, p. 165). Ela é útil quando mobilizada prudentemente, tendo por finalidade restabelecer a harmonia e tranquilidade do Estado. Logo, prescreve-se a dissimulação como forma de assegurar a integridade do bem comum, segundo o decoro e as circunstâncias.

O livro de Míssio é circular, pois a última frase remete à primeira: nas 244 palavras do autor, "a quantidade das citações [em Accetto] não impediu a qualidade do escrito, cujo entendimento da questão pôde ser verificado na trama argumentativa" (MÍSSIO 2012, p. 176). Na introdução, por sua vez, Míssio principia dizendo: "Da vida de Torquato Accetto muito pouco se sabe" (MÍSSIO 2012, p. 13). A análise da trama argumentativa supre, em alguma medida, a névoa que encobre a biografia de Accetto. Inversamente, esta mesma névoa parece conferir certa liberdade à mente investigativa do autor do livro, que busca conhecer, com lente de aumento, os argumentos e pressupostos do tratado accettiano. Desta forma, Edmir Míssio não persegue a intencionalidade do autor, pois Accetto não se define como subjetividade psicologicamente expressiva: o que ele busca, na verdade, é sondar a emulação promovida pelo secretário, que recicla auctores e preceitos que respaldam suas reflexões sobre a dissimulação honesta. Este procedimento é profícuo na medida em que não supõe que Accetto esteja por detrás da sua obra, mas sim nela, na própria escrita. Em outras palavras, o autor é o estilo que ele comunica ao leitor, e seu estilo é produto da emulação, da reposição de predicados que não apenas o secretário domina, mas também o leitor discreto, capacitado a julgar os méritos da imitação.

A brevidade não é somente procedimento accettiano, mas também uma das características que se espera de uma resenha. Por esta razão, convém encerrar esta por aqui: que o leitor preencha suas lacunas com prudência e acate, sem mais delongas, o convite que ela efetua. 


\section{Referências bibliográficas}

ACCETTO, Torquato. Da dissimulação honesta. Tradução de Edmir Missio. São Paulo: Martins Fontes, 2001.

GRACIÁN, Baltasar. A arte da prudência. São Paulo: Martin Claret, 1998.

HANSEN, João Adolfo. O Discreto. In: NOVAES, Adauto. Libertinos e libertários. São Paulo: Companhia das Letras, 1996.

MAQUIAVEL, Nicolau. O príncipe. Comentários de Napoleão Bonaparte. São Paulo: Hemus, 1996.

MÍSSIO, Edmir. A civilidade e as artes de fingir: a partir do conceito de dissimulação honesta de Torquato Accetto. São Paulo: EDUSP, 2012.

PÉCORA, Alcir. Apresentação. In: ACCETTO, Torquato. Da dissimulação honesta. Tradução de Edmir Missio. São Paulo: Martins Fontes, 2001.

SEIXAS, Jacy Alves de. Dissimulação, mentira e esquecimento: formas da humilhação na cultura política brasileira (reflexões sobre o brasileiro jecamacunaímico). In: MARSON, Izabel; NAXARA, Márcia (orgs.). Sobre a humilhação: sentimentos, gestos, palavras. Uberlândia: EDUFU, 2005. 